\section{JUSTIÇA RESTAURATIVA COMO BASE PARA MEDIAÇ̃̃O DE CONFLITOS NA ASSISTÊNCIA SOCIAL EM PONTA GROSSA, ANO 2018}

\section{RESTORATIVE UUSTICE AS A BASIS FOR CONFLICT MEDIATION IN SOCIAL ASSISTANCE IN PONTA GROSSA, YEAR 2018}

\section{JUSTICIA RESTAURATIVA COMOBASE PARA LA MEDIACIÓN DE CONFLICTOS EN LA ASISTENCIA SOCIAL ENPONTA GROSSA, AÑO2018}

Lislei Teresinha Preuss ${ }^{1}$ José Henrique de Góes ${ }^{2}$ Daniele Cristina Bahniuk Mendes ${ }^{3}$

\section{RESUMO}

Este trabalho visa identificar a utilização da Justiça Restaurativa (JR) como forma de efetivação do serviço de mediação familiar previsto no serviço de Proteção e Atendimento Integral à Família (PAIF), nos Centros de Referências de Assistência Social (CRAS) de Ponta Grossa, no primeiro semestre do ano de 2018. Para tanto, objetivou-se denotar a Justiça Restaurativa enquanto política pública, bem como suas características enquanto prática de tratamento de conflitos. Também, demonstrar sua compatibilidade com a previsão de mediação familiar como serviço do PAIF. O estudo, de cunho exploratório, base qualitativa, foi realizado por pesquisa bibliográfica e documental, acerca da JR e do PAIF, bem como de levantamento de dados por meio de entrevistas a fim de verificar a aplicação da prática. Chegou-se a resultados de natureza quanti-qualitativa, que apontaram que a Justiça Restaurativa não vem sendo utilizadas pelos CRAS, sendo que estes encaminham os casos para o Poder Judiciário, mesmo sabendo que poderiam adotar, por si, tais práticas.

\section{PALAVRAS-CHAVE}

Proteção Social. PAIF. Justiça Restaurativa. 


\section{ABSTRACT}

This work aims to identify the use of Restorative Justice (JR) as a way of carrying out the family mediation service provided for in the Protection and Comprehensive Service to the Family service - PAIF, in the Social Assistance Reference Centers - CRAS of Ponta Grossa, in first semester of the year 2018. Therefore, the objective was to denote Restorative Justice as a public policy, as well as its characteristics as a conflict treatment practice. Also, demonstrate its compatibility with the provision of family mediation as a service of the PAIF. The study, of an exploratory nature, with a qualitative basis, was carried out through bibliographical and documentary research, about JR and PAIF, as well as data collection through interviews in order to verify the application of the practice. Results were obtained of a quantitative and qualitative nature, which pointed out that the Restorative Justice has not been used by the CRAS, since they refer the cases to the Judiciary, even though they know that they could adopt such practices on their own.

\section{KEYWORDS}

Social Protection. PAIF. Restorative Justice.

\section{RESUMEN}

Este trabajo tiene como objetivo identificar el uso de la Justicia Restaurativa (JR) como una forma de llevar a cabo el servicio de mediación familiar previsto en el Servicio de Protección y Servicio Integral a la Familia - PAIF, en los Centros de Referencia de Asistencia Social - CRAS de Ponta Grossa, en primer semestre del año 2018. Por lo tanto, el objetivo era denotar la Justicia Restaurativa como una política pública, así como sus características como una práctica de tratamiento de conflictos. Además, demuestre su compatibilidad con la provisión de mediación familiar como un servicio del PAIF. El estudio, de carácter exploratorio, con base cualitativa, se realizó mediante investigación bibliográfica y documental, sobre JR y PAIF, así como la recolección de datos a través de entrevistas para verificar la aplicación de la práctica. Se obtuvieron resultados de carácter cuantitativo y cualitativo, que señalaron que el CRAS no ha utilizado la Justicia Restaurativa, ya que remiten los casos al Poder Judicial, a pesar de que saben que pueden adoptar tales prácticas por su cuenta.

\section{PALABRAS CLAVE}

Protección social. PAIF. La justicia restaurativa. 


\section{INTRODUCÇÃO}

Este trabalho visa identificar a utilização da Justiça Restaurativa como forma de efetivação do serviço de mediação familiar previsto no serviço de Proteção e Atendimento Integral à Família (PAIF), nos Centros de Referências de Assistência Social (CRAS) do Município de Ponta Grossa, no primeiro semestre do ano de 2018.

O PAIF é desenvolvido no âmbito dos CRAS e consiste no trabalho social com famílias, de caráter continuado, visando fortalecer a função protetiva da família, prevenir a ruptura de seus vínculos, promover o acesso e usufruto de direitos e contribuir na melhoria de sua qualidade de vida (BRASIL, 2015). Este serviço foca no desenvolvimento de potencialidades das famílias e o fortalecimento de vínculos familiares e comunitários, por meio de ações de caráter preventivo, protetivo e proativo, integrando o nível de proteção social básica do Sistema Único de Assistência Social (SUAS).

De outro lado, com semelhantes propósitos relativos à manutenção e reestabelecimento de relações e/ou tratamento de conflitos está a Justiça Restaurativa (JR). Essa quer manter o diálogo permanente e participação democrática. Seus três pilares básicos são o foco no dano ou na ofensa cometida, pregação de que os danos ou ofensas geram obrigações e a promoção do engajamento e participação (ZEHR, 2002).

Para Zher (2002, p. 49), trata-se de

[...] um processo para envolver, tanto quanto possível, todos aqueles que têm interesse em determinada ofensa, num processo que coletivamente identifica e trata os danos, necessidades e obrigações decorrentes da ofensa, a fim de promover o restabelecimento das pessoas e endireitar as coisas, na medida do possível.

Para relacionar as práticas da JR e o serviço de mediação do PAIF, denotou-se a Justiça Restaurativa enquanto política pública, a partir dos principais documentos sobre o tema, bem como suas características enquanto prática de tratamento de conflitos, e a literatura base para as políticas, como Zehr (2002)

Estabeleceram-se relações entre os objetivos da prática e aqueles constantes do serviço de mediação familiar do PAIF, a ser realizado nos CRAS. Realizou-se levantamento junto aos CRAS do Município de Ponta Grossa, no primeiro semestre do ano de 2018, a fim de verificar a aplicação da JR por meio desse serviço de mediação familiar.

Assim, o estudo, de cunho exploratório, base qualitativa, foi realizado por pesquisa bibliográfica e documental, acerca da JR e do PAIF, bem como de levantamento de dados por meio de entrevistas a fim de verificar a aplicação da prática, chegando-se a resultados de natureza quanti-qualitativa. 


\section{DESENVOLVIMENTO}

\subsection{MEDIAÇ̃̃O DE CONFLITOS NO ÂMBITO DO PAIF}

O PAIF integra o nível de proteção social básica do SUAS e é o trabalho social continuado com famílias fortalecer sua função protetiva, prevenir a ruptura de seus vínculos, promover seu acesso a direitos e contribuir para sua qualidade de vida. 0 desenvolvimento, potencialidades, aquisições e o fortalecimento de vínculos são previstos para se dar por meio de ações preventivas, protetivas e proativas. (BRASIL, 2009).

Trata-se de dimensões atingidas por vulnerabilidades e riscos sociais que extrapolam a questão econômica. Para a Política Nacional de Assistência Social (PNAS), a família é o grupo de pessoas que se acham unidas por laços consanguíneos, afetivos e/ou de solidariedade, mediando relações entre os sujeitos e a coletividade. É espaço contraditório, com dinâmica marcada por conflitos e, geralmente, desigualdades. É base fundamental no âmbito da proteção social. (BRASIL, 2004)

O PAIF é o principal serviço da proteção social básica que desenvolve o trabalho social com famílias. O CRAS é a estrutura física onde o serviço PAIF é executado, sendo a unidade pública estatal de referência da rede de proteção social básica.

O PAIF objetiva ofertar ações socioassistenciais de prestação continuada, por meio do trabalho social com famílias em situação de vulnerabilidade social, fortalecendo a função protetiva da família, contribuindo à sua qualidade de vida, prevenindo a ruptura dos vínculos, possibilitando a superação de situações de fragilidade social, promovendo aquisições às famílias, potencializando protagonismo e autonomia, promovendo, apoiando as famílias que possuem indivíduos que necessitam de cuidados, por meio da promoção de espaços coletivos de escuta e troca de vivências familiares (BRASIL, 1993). Dentre os usuários, encontram-se famílias cujos vínculos de pertencimento e sociabilidade estão em risco.

Trabalho social com famílias no âmbito do PAIF é o conjunto de procedimentos a partir de pressupostos éticos, conhecimento teórico metodológico e técnico-operativo, com a finalidade de contribuir para a convivência, reconhecimento de direitos e possibilidades de intervenção na vida social de um conjunto de pessoas, unidas por laços consanguíneos, afetivos e/ou de solidariedade (BRASIL, 2012).

Dentre as ações que compõem o PAIF, tem-se: acolhida, oficinas com famílias, ações comunitárias, ações particularizadas, encaminhamentos (BRASIL, 2012). As oficinas são encontros previamente organizados, com objetivos de curto prazo a serem atingidos com um conjunto de famílias, por meio de seus responsáveis ou outros representantes, sob a condução de técnicos de nível superior do CRAS.

\subsection{FUNDAMENTOS DA JUSTIÇA RESTAURATIVA E MARCOS DA POLÍTICA}

As práticas restaurativas podem ser utilizadas em situações em que haja interesse em fortalecer relacionamentos ou solucionar conflitos entre pessoas. Apesar de abranger programas e práticas, é um conjunto de princípios, uma filosofia, pois sua estrutura em si é para pensar as ofensas (ZEHR, 2012). 
Howard Zehr (2012), referindo aos casos de utilização em relação a conflitos, diz que a Justiça Restaurativa é um processo que envolve todos aqueles que sofreram com uma determinada ofensa, e que, de forma coletiva, irá identificar os danos ocorridos, descobrir suas causas, quais as necessidades dos envolvidos e a obrigação do ofensor, o que tem como intuito restabelecer as pessoas e com isso chegar a uma pacificação social.

Ainda, a Justiça Restaurativa não é mediação, mas assim como na mediação, na Justiça Restaurativa pode haver a possibilidade de realização de encontro entre vítimas, ofensores e membros da comunidade, embora a sua abordagem não se limite a um encontro apenas (ZEHR, 2012).

Os programas de Justiça Restaurativa objetivam colocar as decisões nas mãos daqueles que foram mais afetados pelos conflitos, fazendo com que a justiça seja um processo curativo e transformador, que venha com isso a reduzir a possibilidade de futuras ofensas, pois uma vez que as partes ficam satisfeitas e o ofensor especificamente entende o mal que causou à vítima, poderá não reincidir. Mas para atingir tais metas, Zehr (2012) afirma ser necessário que as vítimas estejam envolvidas no processo e saiam dele satisfeitas, ainda, que os ofensores compreendam como suas ações afetaram outras pessoas e com isso assumam a responsabilidade por tais atos.

0 resultado do processo deve ajudar a reparar os danos e tratar das razões que levaram às ofensas, com medidas especiais que atendam às necessidades, tanto da vítima quanto do ofensor, e que ao fim, ambos cheguem a uma sensação de resolução do conflito, sintam-se satisfeitos com o desfecho final do litígio e com isso sejam reintegrados à comunidade (ZEHR, 2012).

A Justiça Restaurativa procura focar em todas as partes envolvidas, ou seja, a vítima, que sofreu a agressão e que deverá ser reparada, mas ao mesmo tempo, o ofensor, porque é preciso saber o que o motivou a realizar tal delito, para tentar evitar que o faça novamente, mas, especialmente, para solucionar aquela situação. Pode ser que o ofensor também tenha sido vítima anteriormente, porém isto não irá eximi-lo de responder pelo seu comportamento socialmente nocivo, mas há satisfação de necessidades, quando há compreensão da motivação (ZEHR, 2012).

Para a Justiça Restaurativa, responsabilizar não é somente punir e sim fazer com que o ofensor reveja seus atos, bem como o impacto que este causou na vida da vítima e com isso repare os danos causados a ela (ZEHR, 2012).

Percebe-se, portanto, que, alguns pressupostos estão presentes, de modo geral, nas práticas restaurativas (ZEHR; TOEWS, 2004):

- Reempoderamento por meio da fala, com a possibilidade de participação na resolução dos conflitos;

- Conexão com o outro: retomada da capacidade de respeito e solidariedade, perdidos, com a fragmentação social. Assim, há a possibilidade de reconhecer infratores e vítimas como indivíduos, em sua totalidade, com histórias próprias, como indivíduos, além de estereótipos;

- A significação/sentido: com a facilitação por outrem, os envolvidos são não têm suas histórias ou narrativas depuradas, de forma que o sentido do conflito e da responsabilização não se perdem;

- Não neutralidade: a juridicidade alternativa se mostra principalmente neste tópico, vez que os envolvidos não são representados ou interpretados por terceiro pretensamente neutro ou não envolvido na situação; 
- Alteridade: trata-se da integração e aprendizado a partir da percepção da dessemelhança;

- Ação curativa: propõe o foco no fato e nas consequências e não em uma pessoa, como a vítima ou autor de uma pretensão de reparação, a partir das causas, possibilitando a reconstrução de laços;

- Responsabilidade compartilhada: entendimento de que o ato foi produzido a partir de situações no seio da comunidade, assim como deverão ser compartilhadas as responsabilidades pela construção das soluções.

Há possibilidade de utilização da Justiça Restaurativa prevista em alguns dispositivos legais, como os referentes à composição civil dos danos expressa nos artigos 72 e 74 da Lei 9.099/95, ensejando a renúncia a queixa ou representação; a medidas referentes a violação de direitos por meio de adolescentes (art. 89 da Lei 9.099/1995); a crimes contra idosos (artigo 94 da Lei 10.741/2003).

A utilização em processos judiciais de diversas competências, como no caso de conflitos familiares, é plenamente possível com o encaminhamento dos autos a Centros Judiciários de Solução de Conflito e Cidadania (CEJUSC), cuja incumbência inclui a realização das práticas, por meio de pessoas capacitadas a partir de cursos ministrados com certificação pelo Conselho Nacional de Justiça (CNJ). Tudo conforme a resolução 125/2010, do referido órgão.

Órgãos responsáveis estão estruturando formas de utilização da Justiça Restaurativa, ante a previsão específica do artigo 35, III, da lei do Sistema Nacional de Sócio Educação (SINASE) (Lei 12594/2012).

É possível perceber que o paradigma de juridicidade composto no Judiciário, com processamento mecanizado, produção de sentidos e efeitos alheios aos envolvidos, com trajetória técnico-processual e formal, tem possibilidades de alternativa, pela Justiça Restaurativa.

A referida resolução, que institui a Política Judiciária Nacional de tratamento adequado dos conflitos de interesses no âmbito do Poder Judiciário assim entende a Justiça Restaurativa. Porém, determina regras que limitam e condicionam as práticas.

Conforme artigos 12 e seguintes da resolução, somente os Tribunais de Justiça, por meio de núcleos específicos, poderão realizar a formação das pessoas que realizarão os procedimentos no âmbito do Judiciário. A formação, porém, deve se dar em cursos de capacitação de cem horas, nos quais a formação teórica referente a Justiça Restaurativa é um entre doze pontos de conteúdo programático, desenvolvidos em apenas $40 \%$ do curso (item 1.1 do anexo I).

Portanto, em conflitos que sejam identificados em Juízo e nos quais o encaminhamento a procedimentos de solução de conflito tenha dele origem, é possível observar que os processos restaurativos ficam adstritos a procedimentos conduzidos por pessoas determinadas pelo Judiciário, com critério único referente a um tipo de capacitação dele proveniente.

\section{PROCEDIMENTOS METODOLÓGICOS}

Tão importante quanto os resultados da pesquisa é relatar o processo que permitiu a realização do produto. É informar o material do qual se baseou os argumentos, de onde foram coletados os dados e com que enfoque foram analisados. Mais que uma formalidade, a indicação da metodologia oferece a 
outras pessoas a possibilidade de refazer o caminho e, desse modo, avaliar com segurança as afirmações que o pesquisador fez (DUARTE, 2002).

Deste modo, informa-se que o tipo de pesquisa utilizada é a exploratória, que tem por foco proporcionar maior familiaridade com o problema, visando deixá-lo mais explícito ou a construir hipóteses. 0 planejamento é bastante flexível, podendo considerar vários aspectos do objeto estudado (GIL, 2002).

A técnica de pesquisa utilizada é documental indireta escrita, como notícias e coleta de bibliografia para estudo do PAIF. No que toca à Justiça Restaurativa, fez-se uso de revisão de literatura, que é a pesquisa básica e essencial para qualquer atividade científica, dado que possibilita a construção da plataforma teórica e é feita com base em materiais já elaborados, sendo que quase todas as pesquisas exigem trabalho dessa natureza, inclusive alguns são feitos exclusivamente por esta forma (MARTINS; THEÓPHILO, 2005).

Relativamente a abordagem quantitativa, a pesquisa se deu por meio de levantamento, que consiste na técnica em que questiona diretamente as pessoas cujo comportamento se deseja conhecer. Isso permite buscar informações junto a um grupo acerca do problema estudado para, em seguida, mediante análise quantitativa, obterem-se as conclusões correspondentes aos dados coletados (GIL, 2002).

Elegeu-se o Município de Ponta Grossa-PR, cujo censo SUAS 2016, classificou-o como um município de grande porte, com mais de trezentos mil habitantes e com três unidades de CRAS em seu território, quais sejam: CRAS 31 de março, CRAS Jardim Carvalho e CRAS Vila Izabel (BRASIL, 2016). Todavia, em consulta ao blog do Departamento de Gestão do SUAS da Fundação de Assistência Social de Ponta Grossa (FASPG), verificou-se que existem dez unidades de CRAS: Cará-Cará, Coronel Cláudio, Jardim Carvalho, Jardim Paraíso, Nova Rússia, Sabará, Santa Luzia, Vila Izabel, Vila 31 de março e Vila XV.

Figura 1 - Territorialização 2018 dos CRAS Ponta Grossa

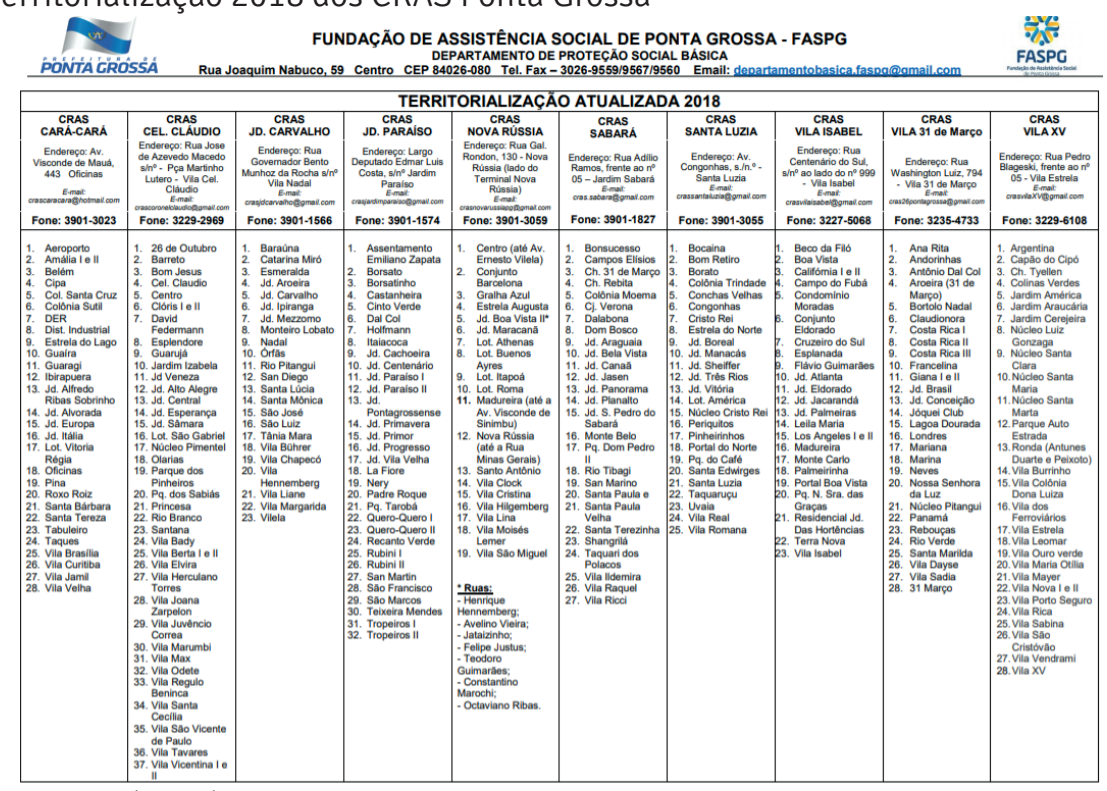

Fonte: Ponta Grossa (2018). 
De posse desta divisão foi possível manter contato com os coordenadores e/ou assistentes sociais de cada uma das unidades, durante o horário de expediente, entre $8 \mathrm{~h}$ e $17 \mathrm{~h}$, dos dias 14 e 15 de maio de 2018. Chegando aos resultados relatados a seguir.

\section{RESULTADO E DISCUSSÕES}

A JR tem uma base principiológica e um instrumental fundados na atenção aos envolvidos, responsabilização e participação dos envolvidos em um conflito ou numa relação, bem como da comunidade, buscando a pacificação, a convivência harmônica, a religação. Trata-se de um processo comunitário em que a palavra "justiça” remete a um valor, não precisando ser usada apenas por operadores do Direito, mas sim por qualquer pessoa de que dela necessita de intervenção restaurativa.

Os CRAS têm a incumbência de desenvolver serviços relacionados ao fortalecimento de vínculos familiares, sendo que uma de suas ações é mediar reuniões familiares. As ações de proteção social básica envolvem a rede, e a JR embasa programa municipal em que a Secretaria de Assistência Social é citada como órgão que poderá promover a implementação das práticas no exercício de suas atividades correntes.

Foram consultados um dos profissionais de cada CRAS, sendo os coordenadores e/ou assistentes sociais de cada uma das unidades. 0 contato se deu via telefone. Nesta pesquisa eles afirmaram que, ao menos, um integrante de cada equipe de CRAS participou de um treinamento acerca da Justiça Restaurativa. Todavia, informaram que o curso teve duração de apenas um dia e tinha um caráter introdutório, de apresentação da Justiça Restaurativa, como princípios e finalidade, sem adentrar nas técnicas e procedimentos. Assim, não se sentiram capacitados o suficiente para replicar as práticas aos demais colegas de trabalho.

Essas constatações refletem diretamente no baixo número de CRAS que realizam mediação de conflitos familiares, apenas dois deles, o CRAS Coronel Cláudio e o CRAS Sabará. Foi frisado pelos profissionais destes CRAS que a mediação se dá em caráter esporádico e em situações bastante peculiares, que não demandam técnicas complexas, podendo ser realizado pela experiência comum e por qualquer pessoa, independentemente de sua formação profissional.

Com isso, é possível extrair que os CRAS em Ponta Grossa não fazem uso frequente e regular das técnicas de Justiça Restaurativa para a mediação de conflitos familiares, salvo dois deles que se utilizam para algumas situações.

Os outros oito CRAS encaminham todos os conflitos, sejam familiares ou não, para o Centro Judiciário de Solução de Conflitos e Cidadania (CEJUSC). As justificativas dos profissionais para essa medida são de três ordens. A primeira é que as unidades dos CRAS, em sua maioria, sequer estão compostas do número mínimo de profissionais previsto na Norma Operacional Básica de Recursos Humanos do SUAS - NOB-RH/SUAS.

Diz a legislação que a composição da equipe de referência dos CRAS para a prestação de serviços e execução das ações no âmbito da Proteção Social Básica nos municípios de grande porte - 5.000 famílias referenciadas - é de 4 técnicos de nível superior, sendo dois profissionais assis- 
tentes sociais, um psicólogo e um profissional que compõe o SUAS, 4 técnicos de nível médio e 1 coordenador (BRASIL, 2012).

A segunda justificativa reside na falta de treinamento específico de toda a equipe para aplicação da Justiça Restaurativa. Como dito anteriormente, foi ofertado apenas um treinamento de curta duração e para um representante de cada CRAS. Assim, eles não se sentem aptos a aplicar com segurança as técnicas da JR.

Por fim, a terceira justificativa é a existência do CEJUSC, um órgão específico composto de pessoas treinadas e com experiência para fazerem as mediações de conflitos de qualquer ordem. Acreditam que o encaminhamento a este órgão traz mais benefícios aos envolvidos, ante a especialidade para cuidar do assunto.

Vale fazer a referência à comunidade do Núcleo Habitacional Santa Luzia, no qual o CEJUSC desenvolve, desde final de 2016, um projeto de Justiça Restaurativa Comunitária, denominado Projeto Pertencer. A intenção é de tornar as comunidades relativamente autônomas na gestão de seus conflitos, assim uma equipe composta por uma juíza coordenadora, uma servidora da prefeitura, dois facilitadores voluntários do CEJUSC e uma moradora, fazem atendimentos todas às terças-feiras, no período da tarde, no espaço da Associação de Moradores (BOURGUIGNON; ORTH, 2017). Assim, o CRAS Santa Luzia encaminha os atendidos para esse projeto ligado ao CEJUSC, cujo atendido ocorre no seio da comunidade.

\section{CONSIDERAÇÕES FINAIS}

A JR está sendo implementada como política pública a partir do Judiciário, propondo a valorização da autonomia das pessoas e o diálogo, oportunizando aos envolvidos que identifiquem claramente suas necessidades, a fim de restabelecer a harmonia entre todos. Igualmente, o PAIF visa manter a função familiar, realizando ações a fim de manter ou reestabelecer vínculos a partir de processos que garantam direitos dos sujeitos, fomentam à autonomia e à emancipação.

Em Ponta Grossa, a JR está prevista para utilização enquanto programa que considera órgãos de diferentes áreas, a fim de que possam utilizar o procedimento e/ou seu conjunto principiológico em atividades cotidianas.

Pelo menos uma pessoa de cada CRAS do Município de Ponta Grossa participou de um dia de sensibilização acerca da JR, porém houve adesão de apenas dois deles, que utilizam a JR como inspiração para implementar a mediação familiar, seja como parte das ações para fortalecimento de vínculo ou em oficinas.

Os CRAS relegam o desenvolvimento das práticas de JR ao CEJUSC. Porém, o órgão funciona fora das comunidades, exceto em um caso, de maneira que o acesso à população se torna mais difícil, seja pela localização, seja pelo tempo despendido em atendimento no CRAS e, então, em outro órgão, a fim de suprirem-se necessidades relativas à proteção social básica.

Para solucionar as questões elencadas pelos técnicos, há a dependência dos gestores, bem como a adesão dos técnicos, a fim de que as ações possam ser desenvolvidas nos CRAS, pois os cursos de 
capacitação têm carga programática que exige em torno de uma semana para desenvolvimento.

Conclui-se que em sendo o CRAS/PAIS um espaço democrático, de trocas de vivências familiares e comunitários, seria de se articular as ações de grupos do PAIF com a metodologia da JR por meio de diálogo sobre os problemas, por meio de círculos de conversa, com os demandantes da assistência social, pela mediação realizada pelo técnico responsável pelo serviço. Esses técnicos (assistentes sociais, psicólogos) podem desenvolver junto ao grupo as alternativas e possibilidades para resoluções de conflitos, identificando as demandas e necessidades de cada participante, para que em conjunto consigam compreender suas potencialidades, assumindo responsabilidades e restaurando relações sociais (GEBELUKA; FIDELIX, 2016).

Nesta ótica, por mais que existam inegáveis dificuldades para se introduzir um programa restaurativo dentro dos CRAS, a tentativa deve ser permanente, porque a JR pode ser o instrumental para a construção de uma política que valorize o sujeito e as relações humanas e sociais.

\section{REFERÊNCIAS}

ARAÚJO, A.P. Justiça restaurativa na escola: estado do conhecimento. Revista Educação por Escrito, Porto Alegre, v. 4, n. 1, p. 7, jul. 2013.

BRASIL. Lei n 8.742, de 7 de dezembro de 1993. Dispõe sobre a organização da Assistência Social e dá outras providências. Disponível em: http://www.planalto.gov.br/ccivil_03/Leis/l8742.htm. Acesso em: 7 jun. 2018.

BRASIL. Conselho Nacional da Assistência Social. Resolução 109/2009. Aprova a Tipificação Nacional de Serviços Socioassistenciais. Disponível em: http://www.mds.gov.br/webarquivos/ publicacao/assistencia_social/Normativas/tipificacao.pdf. Acesso em: 7 jun. 2018.

BRASIL. Ministério do Desenvolvimento Social. Secretaria Nacional de Assistência Social.

Orientações Técnicas Sobre o PAIF. Volume 2. Trabalho com Famílias do PAIF. Brasília, 2012. Disponível em: http://www.mds.gov.br/webarquivos/publicacao/assistencia_social/Cadernos/ Orientacoes_PAIF_2.pdf. Acesso em: 7 jun. 2018.

BRASIL. Conselho Nacional de Assistência Social. Resolução nº 33 de 12 de dezembro de 2012. Aprova a Norma Operacional Básica do Sistema Único de Assistência Social - NOB/SUAS. Disponível em: http://www.mds.gov.br/webarquivos/arquivo/assistencia_social/nob_suas.pdf.

Acesso em: 18 maio 2018.

BRASIL. Ministério do Desenvolvimento Social. Serviço de Proteção e Atendimento Integral à Família - PAIF. Brasília, 2013. Disponível em: http://mds.gov.br/acesso-a-informacao/perguntas- 
frequentes/assistencia-social/psb-protecao-social-basica/projetos-psb/servico-de-protecao-eatendimento-integral-a-familia-2013-paif. Acesso em: 18 maio 2018.

BRASIL. Ministério do Desenvolvimento Agrário e Social. Censo SUAS 2016. Brasília-DF, 2016. Disponível em: https://aplicacoes.mds.gov.br/sagirmps/portal-censo/. Acesso em: 17 maio 2018.

BOURGUIGNON, J. A.; ORTH, G. M. N. Justiça Restaurativa Comunitária: Projeto Pertencer e acesso à justiça. II Simpósio internacional interdisciplinar em ciências sociais aplicadas, 2, 2017, Ponta Grossa. Anais [...], Ponta Grossa: UEPG. Disponível em: http://sites.uepg.br/simposiocsa/docs/ gt6/021.pdf. Acesso em: 18 maio 2018.

DUARTE, R. Pesquisa qualitativa: reflexões sobre o trabalho de campo. Cadernos de Pesquisa. São Paulo, n. 115, p. 139-154, mar. 2002.

GEBELUKA, R. A. D.; FIDELIX, S. C. A Mediação de conflitos a partir do trabalho social com famílias em grupo no âmbito do PAIF. Jornada de Estudos e Pesquisa sobre Justiça Restaurativa, 1, 2016, Ponta Grossa. Anais [...], Ponta Grossa: UEPG - Universidade Estadual de Ponta Grossa, 2016. V. 1.

GIL, Antonio Carlos. Como elaborar projetos de pesquisa. 4 ed. São Paulo: Atlas, 2002. Disponível em: https://professores.faccat.br/moodle/pluginfile.php/13410/mod_resource/content/1/como_ elaborar_projeto_de_pesquisa_-_antonio_carlos_gil.pdf. Acesso em: 18 maio 2018.

MARTINS, Gilberto de Andrade; THEÓPHILO, Carlos Renato. Metodologia da investigação científica para ciências sociais aplicadas. 2. ed. São Paulo, Atlas, 2009. 247p. PONTA GROSSA. Fundação de Assistência Social de Ponta Grossa. Territorialização Atualizada 2018. Disponível em: https://redeassocialpg.files.wordpress.com/2018/02/crasterritorializac3a7c3a3o-atualizada-2018.pdf. Acesso em: 17 maio 2018.

ZEHR, H. Justiça restaurativa. São Paulo: Palas Athena, 2012. 
1 Doutora em Serviço Social pela Pontifícia Universidade Católica do Rio Grande do Sul; Professora do Curso de Serviço Social da Universidade Estadual de Ponta Grossa E-mail: lisleipreuss@hotmail.com

2 Mestre em Ciências Sociais Aplicadas pela Universidade Estadual de Ponta Grossa/Paraná.

E-mail: henriquedegoes@hotmail.com

3 Mestre em Ciências Sociais Aplicadas da Universidade Estadual de Ponta Grossa/Paraná; Professora do Curso de Direito da Universidade Estadual de Ponta Grossa.

E-mail: dcbahniuk@gmail.com

\section{(2) (1) (-)}

Este artigo é licenciado na modalidade acesso abertosob a Atribuição-Compartilhalgual CC BY-SA

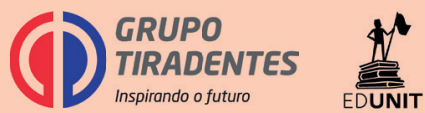

